\title{
Narrowing desiccating crack patterns by an azeotropic solvent for the fabrication of nano-mesh electrodes
}

Rajashekhar Pujar, ${ }^{1,2, \perp}$ Ankush Kumar, ${ }^{1,3, \perp}$ K. D. M. Rao, ${ }^{4}$ Supti Sadhukhan, ${ }^{5}$ Tapati Dutta, ${ }^{6}$ Sujata Tarafdar, ${ }^{7}$ and Giridhar U Kulkarni ${ }^{1, *}$

${ }^{1)}$ Centre for Nano and Soft Matter Sciences, Jalahalli, Bengaluru, 560013, India

${ }^{2)}$ Manipal Academy of Higher Education, Manipal, 576104, India

${ }^{3)}$ Chemistry and Physics of Materials Unit, Jawaharlal Nehru Centre for Advanced Scientific Research, Jakkur, Bengaluru, 560064, India

4) Technical Research Center, Indian Association for the Cultivation of Science, Kolkata, 700032, India

5) Physics Department, Jogesh Chandra Chaudhuri College, Kolkata, 700033, India

6) Physics Department, St. Xavier's College, Kolkata, 700016, India

${ }^{7)}$ Physics department, Jadavpur University, Kolkata, 700032, India

\section{Supporting information}

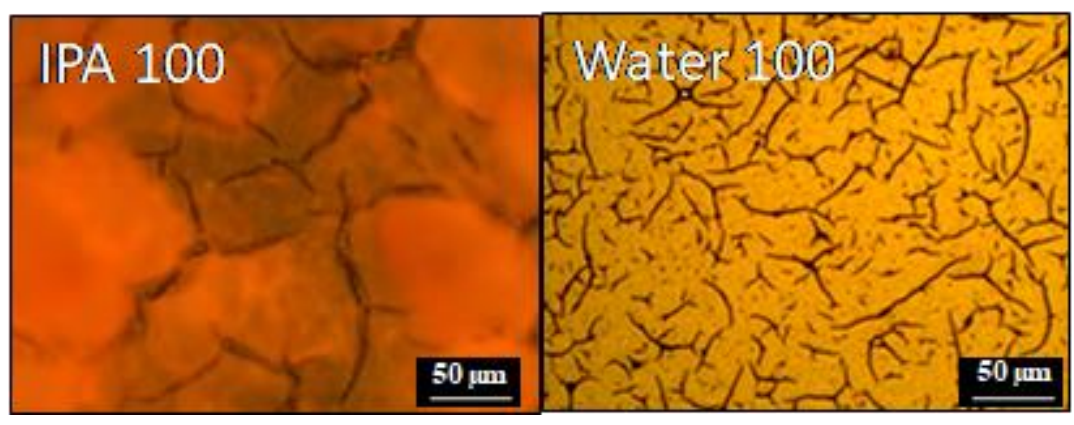

FigureS1. Crack patterns with pure IPA or water as a solvent. Crack patterns are unconnected and have largely isolated cracks.

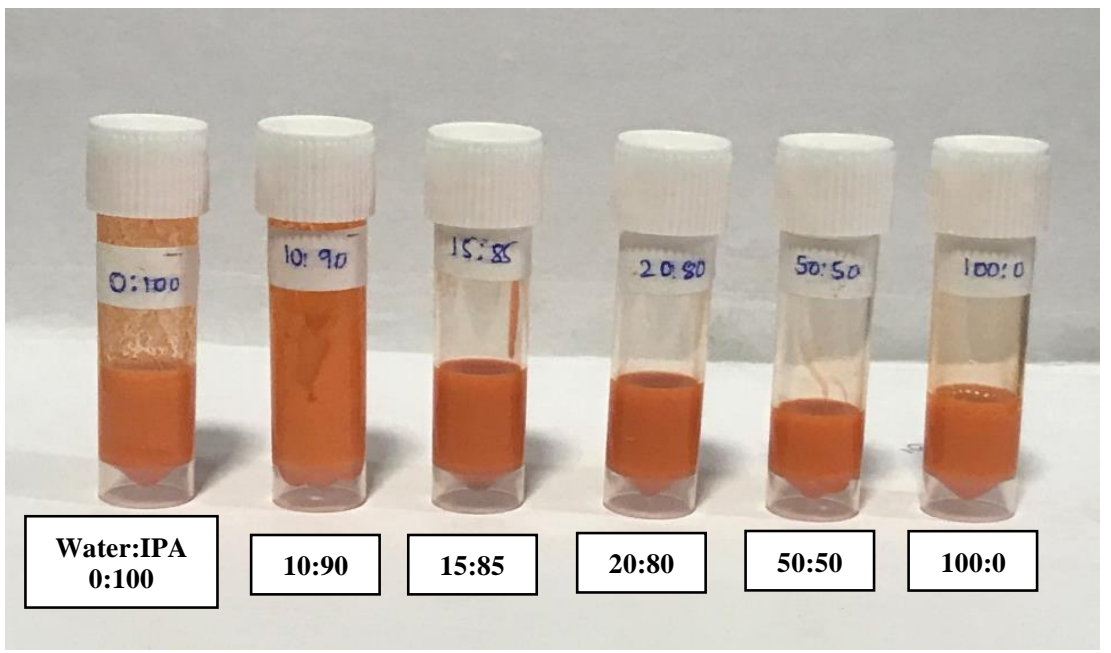

FigureS2. Digital images showing dispersion of crackle precursor at different IPA volume fractions at $0.4 \mathrm{~g} / \mathrm{mL}$ concentration.

Our visual experiments on solubility show that the resin does not form good dispersions for IPA rich compositions (0:100 and 10:90). For water-rich compositions, 100:0, 70:30 and 50:50, the dispersions are relatively stable but settle down in a day, while for those nearing azeotropic compositions (20:80 and 15:85), the dispersions remained stable even after a week. 


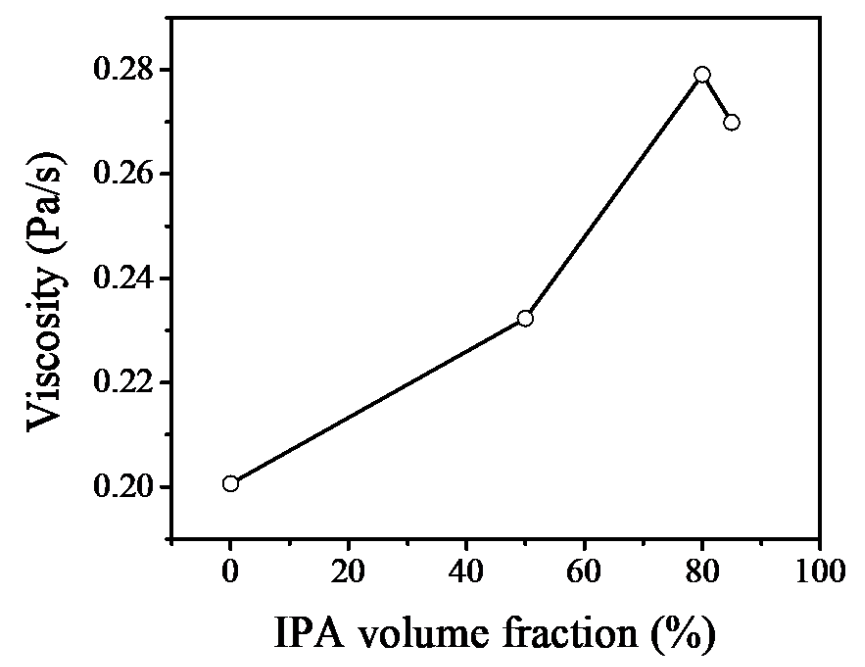

Figure S3: Variation of the viscosity of colloidal dispersion with different IPA volume fraction measured at a shear rate of 10/s. The viscosity increases with increase in IPA volume fraction. The measurements at higher volume fraction could not be performed as higher IPA rich solvents did not form good dispersions.

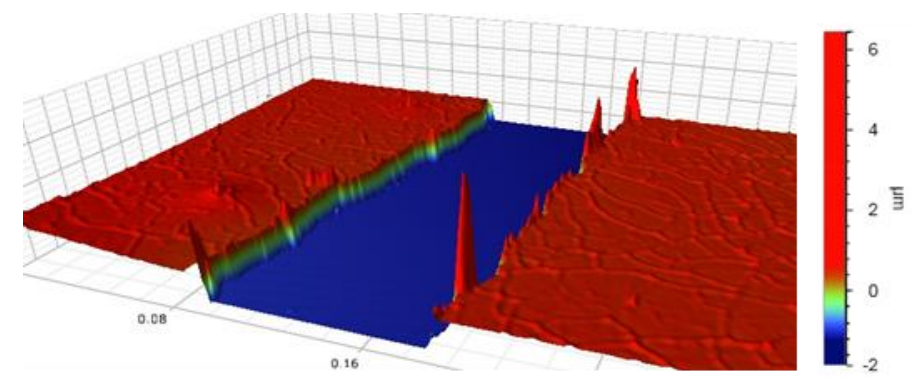

FigureS4. Height profile of crack network measured using optical profilometer

TABLE S1. Comparison of crack width and spacing of different crack patterns from the literature. Theresistancevaluesarenotmentionedasitdependsonfilmthicknesswhichisdifferentindifferent studies.

\begin{tabular}{|c|c|c|c|c|c|}
\hline S.I. No & Material & $\begin{array}{c}\sim \text { Crack width } \\
(\mu \mathrm{m})\end{array}$ & $\begin{array}{c}\text { Crack } \\
\text { spacing } \\
(\mu \mathrm{m})\end{array}$ & $\begin{array}{c}\text { Transmittance } \\
(\%)\end{array}$ & Reference \\
\hline 1 & Paint & 50 & 400 & 77 & 1 \\
\hline 2 & $\begin{array}{c}\mathrm{TiO}_{2} \mathrm{NPs} 318 \\
\mathrm{~K}\end{array}$ & 37 & 210 & 82 & 2 \\
\hline 3 & $\begin{array}{c}\mathrm{TiO}_{2} \mathrm{NPs} 318 \\
\text { K }\end{array}$ & 18 & 140 & 93 & 2 \\
\hline 4 & Egg & 0.5 & 470 & 99.4 & 3 \\
\hline 5 & $\mathrm{TiO}_{2}$ gel & 2 & 35 & 78 & 4 \\
\hline 6 & Acylic resin & $2-6$ & 25 & 82 & 5 \\
\hline 7 & $\begin{array}{c}15: 85 \\
\text { (water:IPA) } \\
\text { with acrylic } \\
\text { resin }\end{array}$ & 0.162 & 12 & 95 & $\begin{array}{l}\text { This } \\
\text { work }\end{array}$ \\
\hline
\end{tabular}



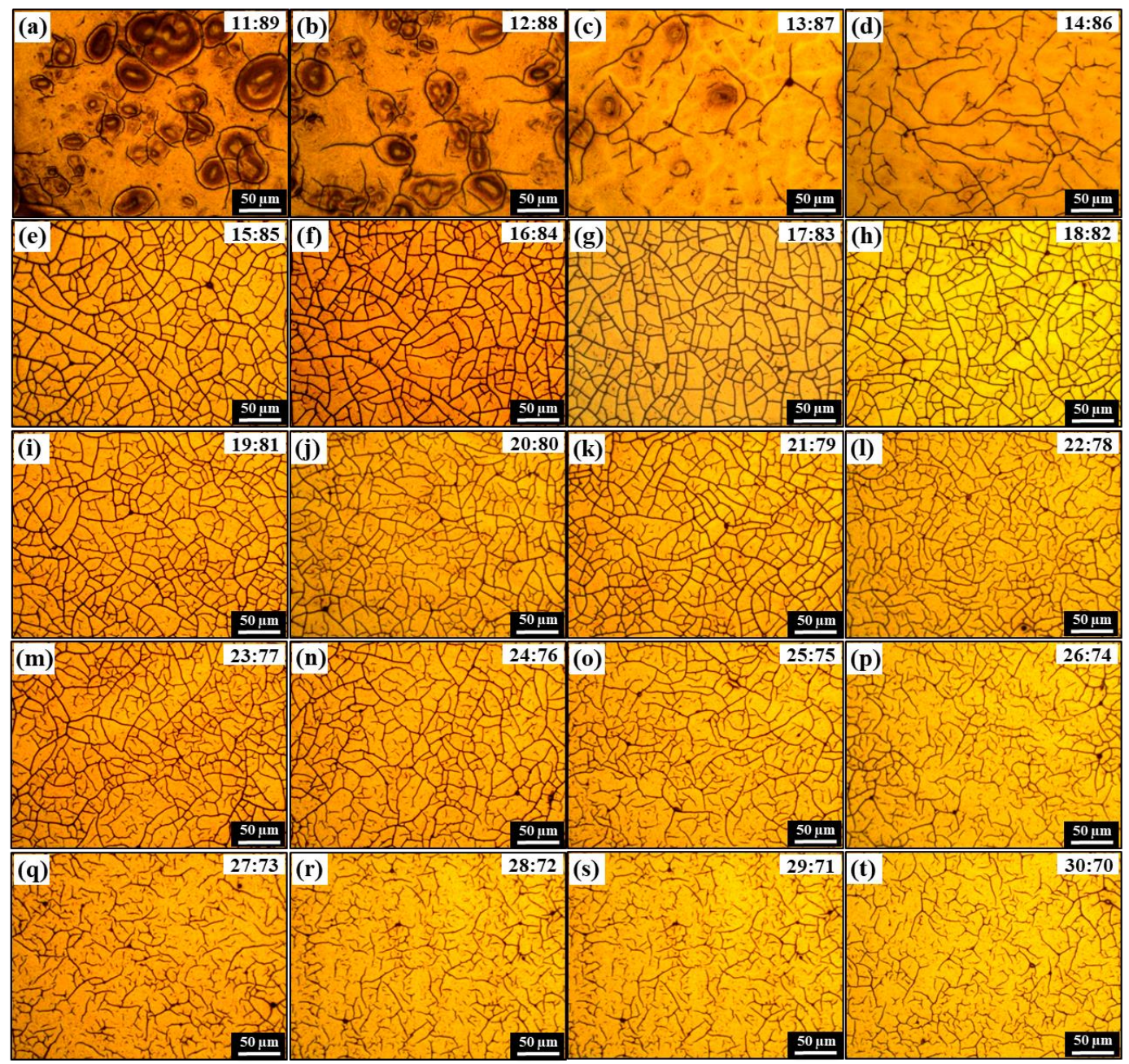

FigureS5. Optical microscopy (a-t) of crack template formation with water:IPA at different volume fractions (11:89-30:70) respectively with concentration $0.35 \mathrm{~g} / \mathrm{ml}$ at $2000 \mathrm{rpm}$
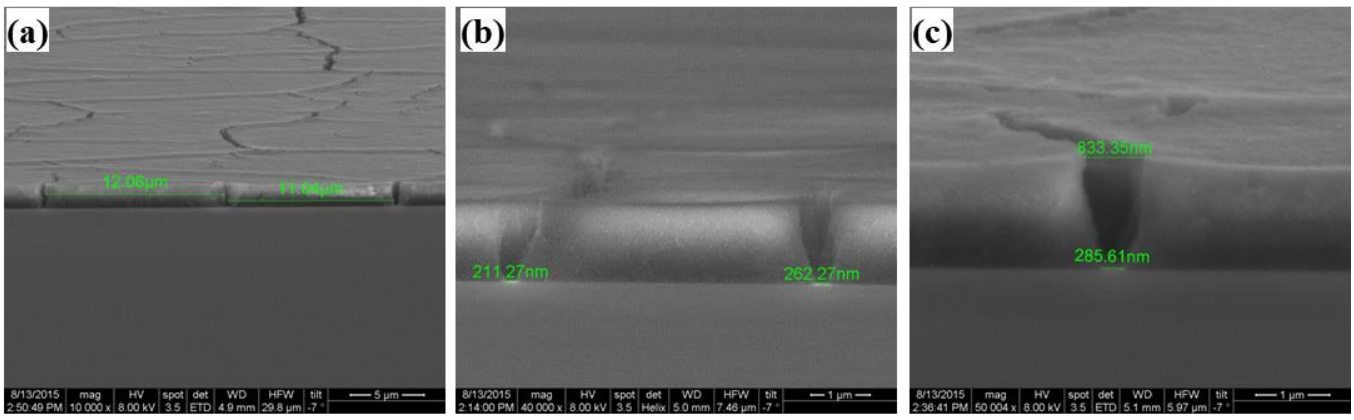

Figure S6. Cross-sectional of crack template. 

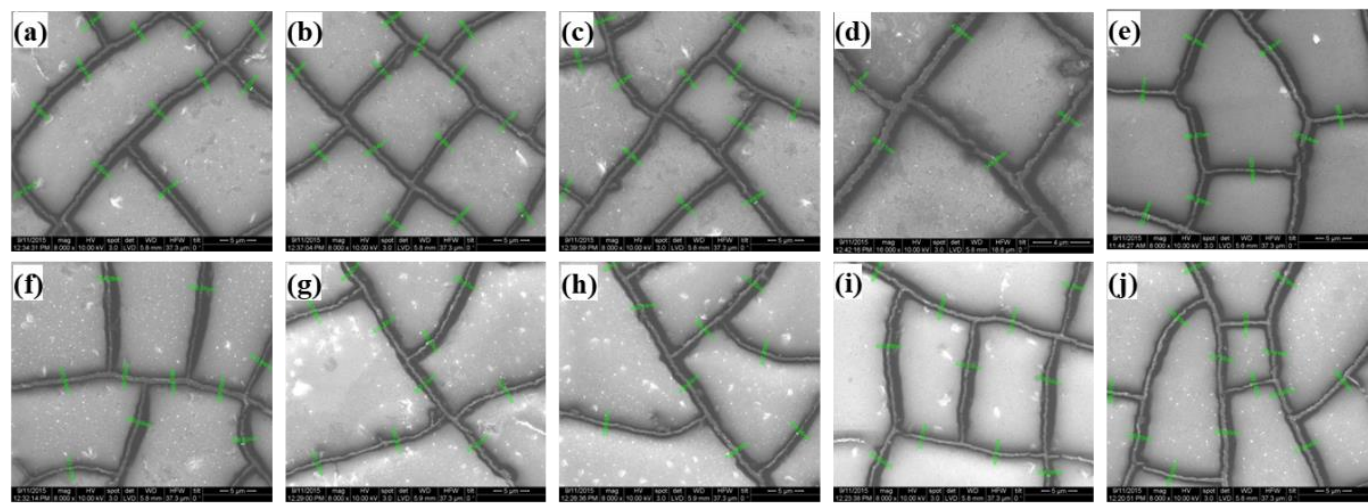

(h)

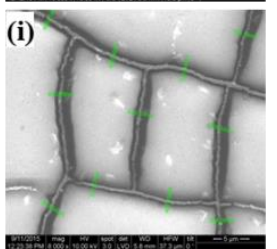

(j)

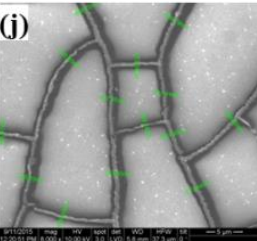

Figure S7. SEM images (a-j) showing crack width measurements carried out at different locations on 15:85 (water:IPA) mixture as a solvent sample.

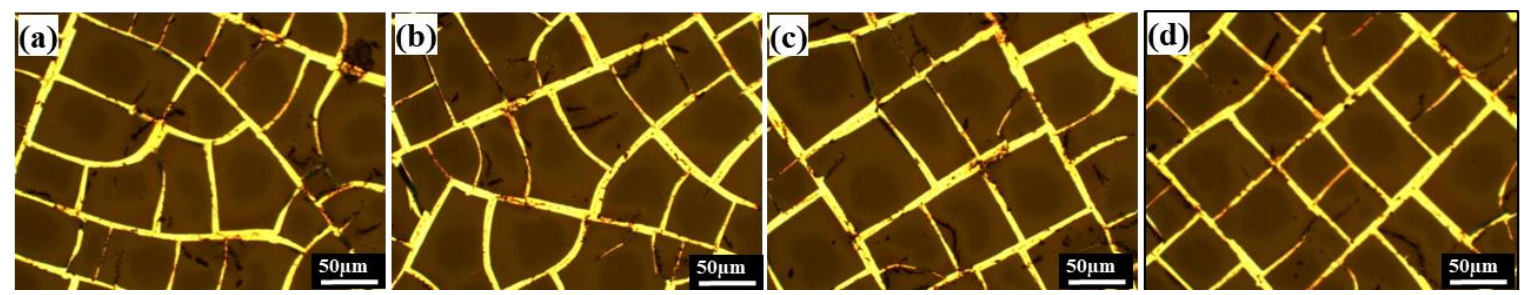

Figure S8. Optical microscopy images (a-d) showing crack width measurements carried out at different locations on diluter as a solvent sample.
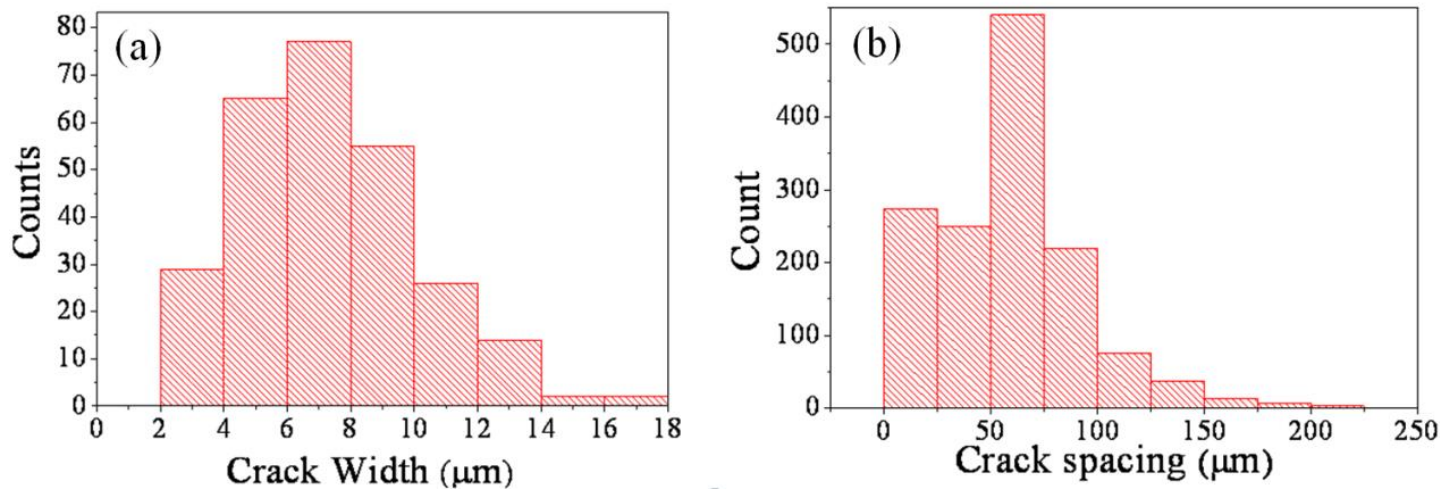

Figure S9. Histogram shows the crack width and spacing with diluter (a and b) as solvent. 


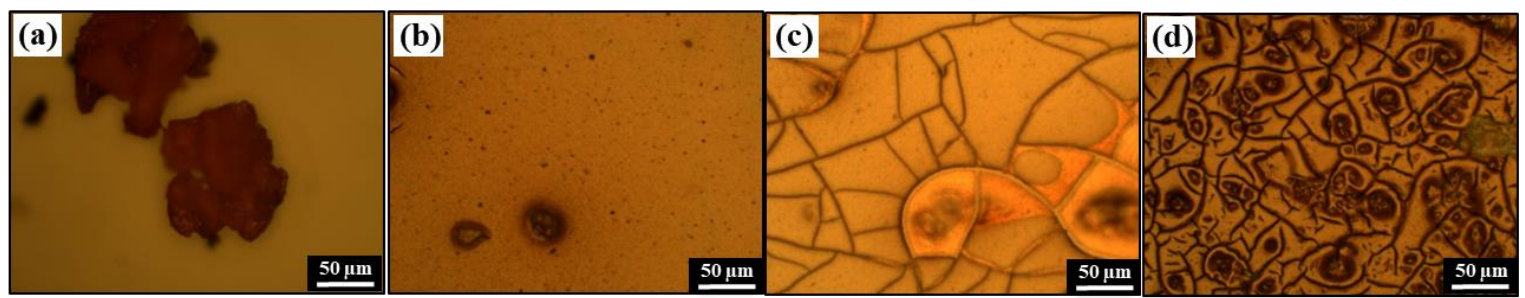

Figure S10. Optical microscopy images show Crack patterns obtained using individual solvents Acetone (a), DMF (b), Ethanol (c) and Chloroform (d), as a solvent. Crack patterns are either unconnected cracks or have non-uniform cracks with lumps.

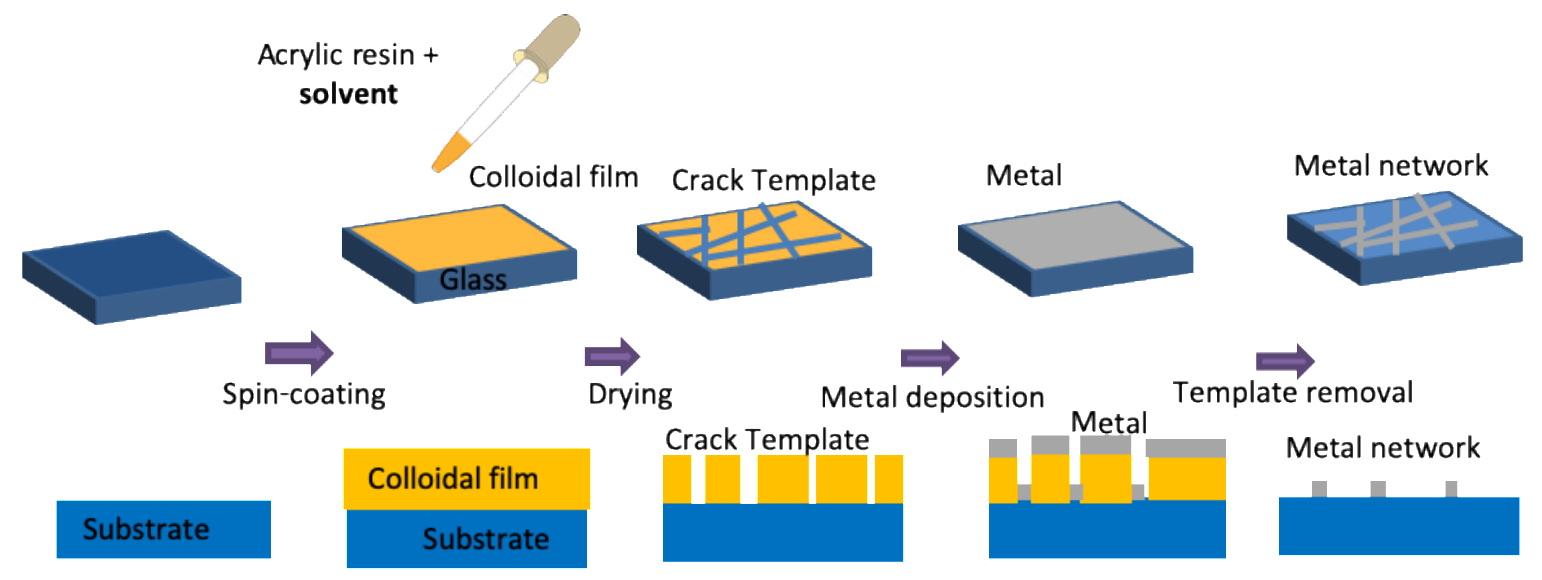

Figure S11. Schematic representation of the steps for the fabrication of TCE obtained from crack template with acrylic resin as crack precursor mixed with particular solvent, which is commercial diluter or 15:85 (water:IPA) in the present study.

Kiruthika, S.; Gupta, R.; Kulkarni, G. U., Large area defrosting windows based on electrothermal heating of highly conducting and transmitting Ag wire mesh. RSC Adv. 2014 4(91), 49745-49751.

2 Kiruthika, S,; Rao, K.; Kumar, A.; Gupta, R.; Kulkarni, G. U., Metal wire network based transparent conducting electrodes fabricated using interconnected crackled layer as template. Mater. Res. Express 2014, 1 (2), 026301.

3 Peng, Q. a. L., Songru and Han, Bing and Rong, Qikun and Lu, Xubing and Wang, Qianming and Zeng, Min and Zhou, Guofu and Liu, Jun-Ming and Kempa, Krzysztof and others, Colossal Figure of Merit in TransparentConducting Metallic Ribbon Networks. Advanced Materials Technologies 2016, 1 (6).

$4 \quad$ Han, B.; Pei, Ke.; Huang, Y.; Zhang, X.; Rong, Q.; Lin, Q.; Guo, Y.; Sun, T.; Guo C.; Carnahan, D.; Giersig, M.; Wang, Y.; Gao, J.; Ren, Z.; Kempa, K., Uniform Self-Forming Metallic Network as a High-Performance Transparent Conductive Electrode.Advanced Materials 2014, 26 (6), 873-877.

5 Rao, K. D. M.; Gupta, R.; Kulkarni, G. U., Fabrication of Large Area, High-Performance, Transparent Conducting Electrodes Using a Spontaneously Formed Crackle Network as Template. Adv. Mater. Interf. 2014, $1(6)$. 